\title{
Chemokines and peripheral nerve demyelination
}

\author{
T Fujioka, DL Kolson and AM Rostami \\ Department of Neurology, University of Pennsylvania Medical School, 3400 Spruce Street, Philadelphia, Pennsylvania \\ 19104, USA
}

\begin{abstract}
It has been speculated that $\beta$-chemokines play a pivotal role in the development of peripheral nervous system (PNS) disorders characterized by mononuclear cell infiltration. In experimental allergic neuritis (EAN), an animal model for human Guillain-Barré syndrome (GBS) with mononuclear cell infiltration, we found by quantitative PCR that $\beta$-chemokine messages were upregulated during the active stage. Moreover, an increase in the monocyte chemoattractant protein-1 (MCP-1) message was found in the preclinical stage of EAN, suggesting the critical role of MCP-1 for inducing mononuclear cell infiltrations in this model. Since many cell lineages other than immune cells can produce chemokines, this early upregulation of MCP-1 may be mediated by non-immune cells, probably endothelia or Schwann cells. To date, apart from MCP-1, only RANTES (Regulated on activation, normal $T$ cell expressed and secreted) and macrophage inflammatory protein (MIP)-1 $\alpha$ have been examined in EAN and found to have similar kinetics of induction. Therefore, understanding the regulation of production of these chemokines as well as mechanisms of inhibiting chemokine/receptor interactions in the PNS may ultimately lead to disease-specific therapy for GBS and related demyelinating disorders.
\end{abstract}

Keywords: chemokines; peripheral nervous system; experimental allergic neuritis; Schwann cells

\section{Introduction}

The role of chemokines (CK) in peripheral nervous system (PNS) disease is suggested by a number of experimental observations demonstrating leukocyte infiltration around peripheral nerve fibers in inflammatory neuropathies (Prineas, 1981). In many PNS diseases, even in non-inflammatory PNS diseases like hereditary polyneuropathy, ischemic neuropathy or axonal degeneration after sciatic nerve transection, mononuclear cell infiltration is involved during the development of pathological changes (Cornblath et al, 1990; Venezie et al, 1995). Since CK play a pivotal role in leukocyte trafficking into the CNS (Proost et al, 1996; Baggiolini, 1998), it has been hypothesized that they play a similar role in the PNS (Adamus et al, 1997; Eng et al, 1996; Godiska et al, 1995; Karpus et al, 1995; Glabinski et al, 1997; Ransohoff et al, 1996).

The PNS is comprised of relatively fewer cell elements than the CNS: Schwann cells, peripheral

Correspondence: AM Rostami

Received 31 August 1998; accepted 9 September 1998 nerve axons, fibroblasts, endothelia, pericytes and macrophages (Thomas et al, 1993). Among these cell types, Schwann cells (SC) are possibly the only cell lineage that is unique to the PNS. SC have analogous functions to oligodendrocytes and astrocytes in the CNS: myelination of axons and maintenance of the homeostasis of the neuron, respectively. In addition to these roles, SC also have an immunological role, that of antigen presentation (Gold et al, 1995; Armati and Pollard, 1996) and cytokine production (Armati and Pollard, 1996; Bolin et al, 1995; La Fleur et al, 1996). Recently, the ability of SC to produce one of the $\beta$ chemokines, monocyte chemoattractant protein (MCP)-1, in vitro has been shown (Polydefkis et al, 1998). Moreover, cell lineages other than SC found in the PNS such as fibroblasts and endothelia are a well known cell source for CK. However, to date, expression of only MCP-1, MIP- $1 \alpha$ and RANTES has been characterized in the PNS using experimental allergic neuritis (EAN), an animal model for Guillain-Barré syndrome. Here we review the present status of CK studies in the PNS, mainly in EAN, and we present our own data concerning $\beta$ chemokine expression in EAN. 
Monocyte chemoattractant protein (MCP)-1 production in experimental allergic neuritis MCP-1, a well characterized $\beta$-chemokine, is produced by many cell lineages including monocytes, macrophages, lymphocytes, fibroblasts, endothelia, epithelia (Struyf et al, 1998; Douglas et al, 1997), and astrocytes (Adamus et al, 1997; Glabinski et al, 1997; Sun et al, 1997). Its target cells are monocytes, T lymphocytes and NK cells, but not neutrophils (Gu et al, 1997; Schall, 1994; Vaddi et al, 1997) and while a role for MCP-1 in EAE has been proposed (Karpus, 1995) its potential role in experimental allergic neuritis (EAN) has yet to be fully explored. EAN is an animal model for human demyelinating polyneuritis or Guillain-Barré syndrome (GBS). EAN, usually induced in Lewis rats, is mediated by Th1 cells and has a monophasic disease course, with spontaneous recovery (Rostami et al, 1985, 1990). Since the major cell populations seen in the PNS of patients with GBS or rats with EAN are macrophages and lymphocytes (Schmidt et al, 1996; Asbury et al, 1969; Rosen et al, 1992; Zettl et al, 1996), the involvement of $\beta$-chemokines in the development of EAN is strongly suspected.

Recently the kinetics of $\beta$-chemokines (MIP- $1 \alpha$, MCP-1 and RANTES) in EAN peripheral nerves has been clarified (Spies et al, 1997). In this study, the messages of $\beta$-chemokines were found to increase in concert with the clinical signs of EAN. In our studies, we have assessed the kinetics of $\beta$ chemokine mRNA expression in rat cauda equina using quantitative competitive RT - PCR. To do this, we immunized Lewis rats with synthetic peptide SP26 corresponding to the 53-78 amino-acid sequence of the bovine myelin $\mathrm{P} 2$ protein to obtain severe clinical disease (Rostami et al, 1990) (Figure 1). We found that MCP-1 message increases significantly at day 7 post immunization (p.i.), and that the message remained at a high level during the active disease stage (from days 10-17 p.i.), then returned to a normal level at day 20 p.i. (Figure 2). Since the influx of mononuclear infiltrating cells such as macrophages and lymphocytes begins at the clinical onset of EAN (Rosen et al, 1992; Zettl et al, 1996), our data suggest that the upregulation of MCP-1 preceding the clinical onset of EAN may attract these mononuclear cells and cause cell infiltration.

MCP-1 can be produced by SC in vitro upon stimulation by TNF- $\alpha$ or IFN- $\gamma$, or it may appear within 1 day after nerve transection in vivo (Polydefkis et al, 1998). In addition, MCP-1 production by other cell lineages is stimulated by IL-1 (Schwarz et al, 1997) and IL-6 (Biswas et al, 1998). Interestingly, MCP-1 expression is suppressed by Th2 cytokines IL-4, IL-10 and IL-13 (Kucharzik et al, 1998).

These studies raise the question of the relationship between other pro-inflammatory cytokines and MCP-1 in the induction of EAN. Most pro-inflam-

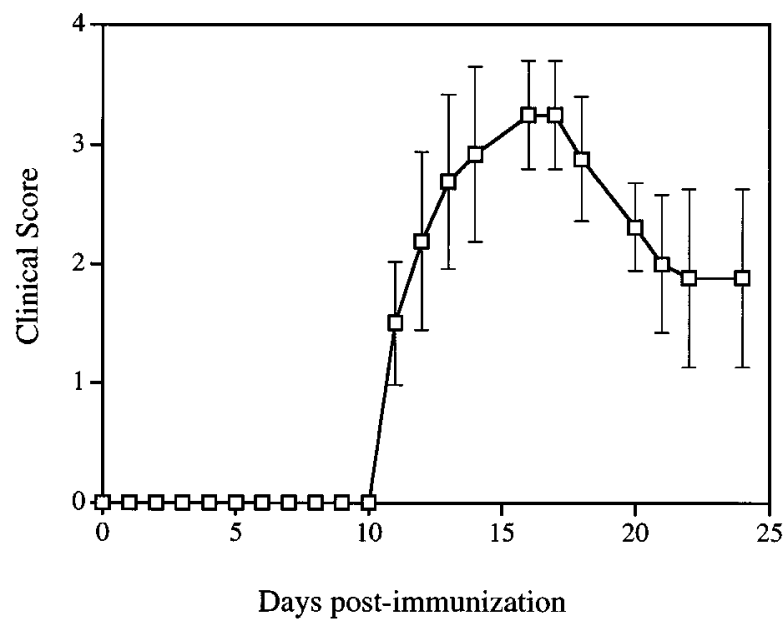

Figure 1 Clinical course of EAN. Average score is shown by solid line. Bars indicate s.d. $\mathrm{n}=24$ (days $0-7$ post immunization, p.i.), 20 (days $8-10$ p.i.), 16 (days $11-13$ p.i.), 12 (days $14-17$ p.i.), 8 (days $18-20$ p.i.) and 4 (days $21-24$ p.i.), respectively. Female Lewis rats were immunized with $150 \mathrm{mg}$ of HPLCpurified SP26. Clinical onset of EAN was day 11 p.i. Peak of disease was observed at days 16 and 17 p.i.; thereafter clinical recovery took place. Clinical scores were given as follows: $0=$ normal; $1=\operatorname{limp}$ tail; $2=$ paraparesis; $3=$ paraplegia; $4=$ quadriplegia (Rostami et al, 1990).

matory cytokines are upregulated during the acute stage while anti-inflammatory cytokines like TGF- $\beta$ and IL-10 are upregulated just before clinical recovery starts (Fujioka et al, 1998; Zhu et al, 1998). Therefore it is possible that MCP-1 is upregulated by pro-inflammatory cytokines during the disease-accelerating stage (from preclinical to peak stages), while it is downregulated by antiinflammatory cytokines during disease recovery stage. Our data suggest that the production of MCP-1 in the PNS during EAN is strongly regulated by cytokines: specifically, upregulation by proinflammatory cytokines and downregulation by anti-inflammatory cytokines. This hypothesis can explain how MCP-1 is regulated after clinical onset; however, it remains unclear what first triggers the upregulation of MCP-1 before overt mononuclear cell infiltration. Production of IL- $1 \beta$ from recruiting neuritogenic $\mathrm{T}$ cells is a possible explanation since IL-1 $\beta$ is upregulated in the early stage of EAN (Zhu et al, 1998) and can upregulate MCP-1 production (Schwarz et al, 1997). In EAN, neuritogenic T cells must invade the PNS to initiate tissue-specific immune response and demyelination before clinical onset. Once these neuritogenic $\mathrm{T}$ cells meet specific antigens in the PNS they may produce proinflammatory cytokines as well as chemokines. The pro-inflammatory cytokines upregulate other proinflammatory cytokines and chemokines, increase the permeability of the blood-nerve barrier, activate invading cells, and sometimes cause tissue damage 


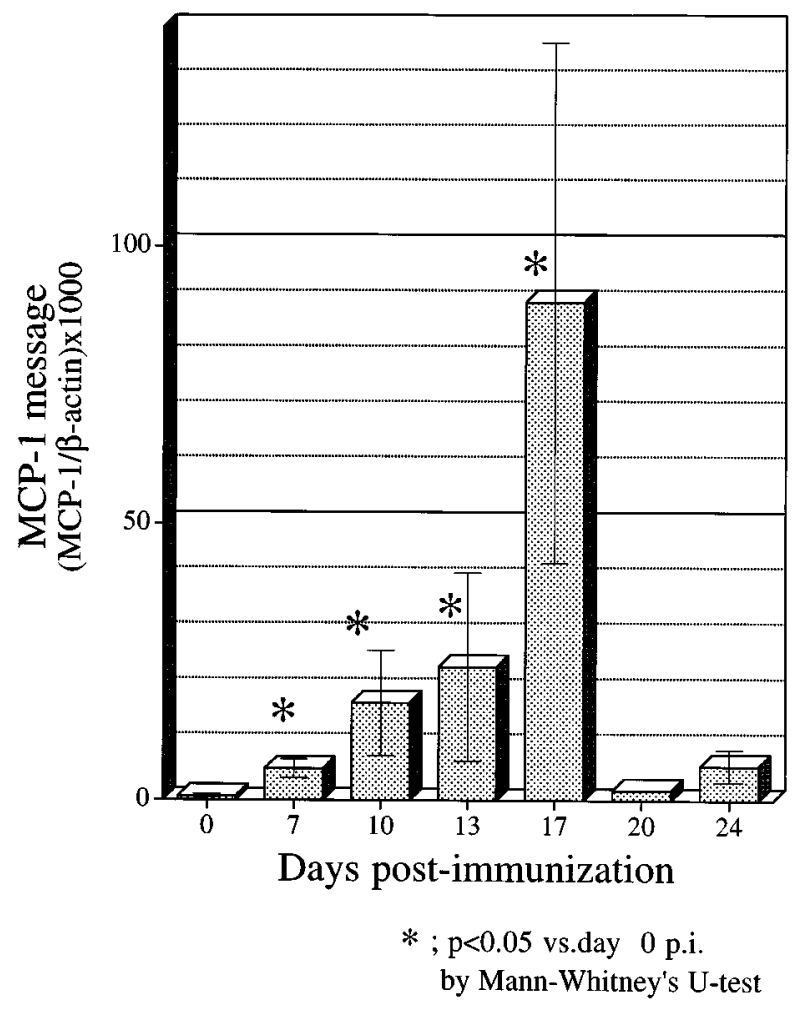

Figure 2 The expression of MCP-1 message in the cauda equina of Lewis rats with experimental allergic neuritis. Total RNA was isolated from caudae equinae removed from rats at different time points, reverse transcribed by Molony Murine Leukemia Virus reverse transcriptase with Oligo (dT) primer. Replicated cDNA was amplified using competitive quantitative PCR (Fujioka et al, 1998). Message of MCP-1 is expressed as a ratio of $\beta$-actin message in the same rats. In this graph, MCP-1 message is shown as an average of four rats in each time point. Bars indicate s.e. Message of MCP-1 increased from days 7-17 p.i. significantly. There was no statistically significant difference within these days (days 7-17 p.i.). MCP-1 message at days 20 and 24 p.i. declined to normal level.

(Lisak et al, 1997). Upregulated CK attract monocytes/macrophages from the blood stream to the PNS, together with cytokines, resulting in intense inflammation in the PNS. This process can be initiated by IL- $1 \beta$ or MCP-1, although the initial signal for this process remains unclear.

As mentioned above, MCP-1 can be produced not only by immune cells but by many other cell

\section{References}

Adamus G, Machnicki M, Amundson D, Adlard K, Offner H (1997). Similar pattern of MCP-1 expression in spinal cords and eyes of Lewis rats with experimental autoimmune encephalomyelitis associated anterior uveitis. J Neurosci Res 50: 531-538.

Armati PJ, Pollard JD (1996). Immunology of the Schwann cell. Baillieres Clin Neurol 5: 47-64. lineages found in both the CNS and PNS. While it is assumed that these cells (SC, fibroblasts, endothelia, epithelia, smooth muscle, monocytes, macrophages, lymphocytes and fibroblasts) are the source of $\beta$-chemokines in the PNS, this hypothesis has yet to be confirmed. Thus, important questions concerning the origin and regulation of chemokine expression in the PNS remain, and are the focus of current investigations in our laboratory.

\section{Macrophage inflammatory protein (MIP)-1 $\alpha$ and Schwann cells}

MIP- $1 \alpha$ acts as prostaglandin pathway-independent pyrogen in addition to its role in inducing chemotaxis (Minano et al, 1996; Armengol et al, 1997), suggesting pleiotropic effects. Notably, a suppressor role for MIP- $1 \alpha$ against astrocyte growth as well as stimulation of SC growth has been demonstrated (Khan and Wigley, 1994). These effects on glial cell growth by MIP- $1 \alpha$ may be important for the remyelination of peripheral nerve during the recovery stage of EAN. Thus, upregulation of MIP- $1 \alpha$ may, as with other $\beta$-CKs, cause an influx of mononuclear cells but, unlike other $\beta$-CKs, MIP- $1 \alpha$ may also help remyelination.

Finally, the $\beta$-CK RANTES (Regulated on activation, normal T cell expressed and secreted) may also have a role in EAN. Although its cell source is still unclear, the stimuli for RANTES upregulation and inhibition, and its target cells are similar to those of MCP-1 (Schall, 1994). In fact, in EAE, the animal model for human multiple sclerosis and the CNS counterpart of EAN, RANTES production is similar to MCP-1 (Glabinski et al, 1997; Godiska et al, 1995; Ransohoff et al, 1996). In EAN, RANTES shows a similar pattern of secretion as MCP-1 and MIP- $1 \alpha$ (Spies et al, 1997). Thus, evidence suggests a role for multiple $\beta$-chemokines in the pathogenesis of EAN and, similar to recent studies in EAE, further analysis of the role of $\beta$-chemokines in peripheral demyelination may lead to the rational design of targeted pharmacological therapeutics for demyelinating peripheral nerve disorders (Ransohoff, 1997).

\section{Acknowledgment}

This work was supported in part by NIH grant NS11037.

Armengol JA, Benamar K, Fernandez-Alonso A, Sancibrian M, Myers RD, Minano FJ (1997). Antibodies to macrophage inflammatory protein-1beta in preoptic area of rats fail to suppress PGE2 hyperthermia. Brain Res 748: $245-249$. 
Asbury AK, Arnason BG, Adams RD (1969). The inflammatory lesion in idiopathic polyneuritis. Its role in pathogenesis. Medicine 48: 173-215.

Baggiolini M. (1998). Chemokines and leukocyte traffic. Nature 392: $565-568$.

Biswas P, Delfanti F, Bernasconi S, Mengozzi M, Cota M, Polentarutti N, Mantovani A, Lazzarin A, Sozzani S, Poli G (1998). Interleukin-6 induces monocyte chemotactic protein-1 in peripheral blood mononuclear cells and in the U937 cell line. Blood 91: 258-265.

Bolin LM, Verity AN, Silver JE, Shooter EM and Abrams JS (1995). Interleukin-6 production by Schwann cells and induction in sciatic nerve injury. J Neurochem 64: $850-858$

Cornblath DR, Griffin DE, Welch D, Griffin JW, McArthur JC (1990). Quantitative analysis of endoneurial T-cells in human sural nerve biopsies. J Neuroimmunol 26: $113-118$.

Douglas MS, Ali S, Rix DA, Zhang JG, Kirby JA (1997). Endothelial production of MCP-1: modulation by heparin and consequences for mononuclear cell activation. Immunology 92: 512-518.

Eng LF, Ghirnikar RS, Lee YL (1996). Inflammation in EAE: role of chemokine/cytokine expression by resident and infiltrating cells. Neurochem Res: 21: $511-525$

Fujioka T, Jimi T, Hilliard BA, Ventura ES, Rostami A (1998). The expression of cytokine mRNA in the cauda equina of Lewis rats with experimental allergic neuritis. J Neuroimmunol 84: 223-229.

Glabinski AR, Tani M, Strieter RM, Tuohy VK, Ransohoff RM (1997). Synchronous synthesis of alpha- and betachemokines by cells of diverse lineage in the central nervous system of mice with relapses of chronic experimental autoimmune encephalomyelitis. $\mathrm{Am} J$ Pathol 150: $617-630$.

Godiska R, Chantry D, Dietsch GN, Gray PW (1995). Chemokine expression in murine experimental allergic encephalomyelitis. J Neuroimmunol 58: 167-176.

Gold R, Toyka KV, Hartung HP (1995). Synergistic effect of IFN-gamma and TNF-alpha on expression of immune molecules and antigen presentation by Schwann cells. Cell Immunol 165: 65-70.

$\mathrm{Gu}$ L, Rutledge B, Fiorillo J, Ernst C, Grewal I, Flavell R, Gladue R, Rollins B (1997). In vivo properties of monocyte chemoattractant protein-1. J Leukocyte Biol 62: $577-580$.

Karpus WJ, Lukacs NW, McRae BL, Strieter RM, Kunkel SL, Miller SD (1995). An important role for the chemokine macrophage inflammatory protein-1 alpha in the pathogenesis of the $\mathrm{T}$ cell-mediated autoimmune disease, experimental autoimmune encephalomyelitis. J Immunol 155: 5003-5010.

Khan S, Wigley C (1994). Different effects of a macrophage cytokine on proliferation in astrocytes and Schwann cells. Neuroreport 5: 1381-1385.

Kucharzik T, Lugering N, Pauels HG, Domschke W, Stoll R (1998). IL-4, IL-10 and IL-13 down-regulate monocyte-chemoattracting protein-1 (MCP-1) production in activated intestinal epithelial cells. Clin Exp Immunol 111, $152-157$

La Fleur M, Underwood JL, Rappolee DA, Werb Z (1996). Basement membrane and repair of injury to peripheral nerve: defining a potential role for macrophages, matrix metalloproteinases, and tissue inhibitor of metalloproteinases-1. J Exp Med 184: 2311-2326.
Lisak RP, Skundric D, Bealmear B, Ragheb S (1997). The role of cytokines in Schwann cell damage, protection and repair. J Inf Dis 176: S173-179.

Minano FJ, Fernandez-Alonso A, Myers RD, Sancibrian $M$ (1996). Hypothalamic interaction between macrophage inflammatory protein-1 alpha (MIP-1 alpha) and MIP-1 beta in rats: a new level for fever control? J Physiol 491: 209-217.

Polydefkis MJ, Krivacic K, Tani M, Ransohoff RM, Griffin JW, Ho TW (1998). Rat Schwann cell upregulate MCP1 synthesis in response to TNF alpha and IFN gamma. Neurology 50: A184.

Prineas JW (1981). Pathology of the Guillain-Barré syndrome. Ann Neurol 9 (suppl): 6-19.

Proost P, Wuyts A, van Damme J (1996). The role of chemokines in inflammation. Int J Clin Lab Res 26: $211-223$.

Ransohoff RM, Glabinski A, Tani M (1996). Chemokines in immune-mediated inflammation of the central nervous system. Cytokine and Growth Factor Rev 7: $35-46$.

Ransohoff RM (1997). Chemokines in neurological disease models: correlation between chemokine expression patterns and inflammatory pathology. $J$ Leukocyte Biol 62: 645-652.

Rosen JL, Brown MJ, Rostami A (1992). Evolution of the cellular response in P2-induced experimental allergic neuritis. Pathobiology 60: 108-112.

Rostami A, Burns JB, Brown MJ, Rosen J, Zweiman B, Lisak RP, Pleasure DE (1985). Transfer of experimental allergic neuritis with P2-reactive T-cell lines. Cell Immunol 91: $354-361$.

Rostami A, Gregorian SK, Brown MJ, Pleasure DE (1990) Induction of severe experimental autoimmune neuritis with a synthetic peptide corresponding to the 53-78 amino acid sequence of the myelin P2 protein. $J$ Neuroimmunol 30: 145-151.

Schall T (1994). The Chemokines. In: Thomson A (ed). The cytokine handbook. Academic Press, London.

Schmidt B, Toyka KV, Kiefer R, Full J, Hartung HP, Pollard J (1996). Inflammatory infiltrates in sural nerve biopsies in Guillain-Barré syndrome and chronic inflammatory demyelinating neuropathy. Muscle \& Nerve 19: $474-487$.

Schwarz M, Radeke HH, Resch K, Uciechowski P (1997). Lymphocyte-derived cytokines induce sequential expression of monocyte- and T cell-specific chemokines in human mesangial cells. Kidney Int 52: 1521-1531.

Spies J, Sheikh K, Tani M, Krivacic K, Ransohoff R, Griffin J (1997). Chemokine mRNA expression in experimental allergic neuritis. Peripheral Nerve Society, Cambridge, England.

Struyf S, Van Collie E, Paemen L, Put W, Lenaerts JP, Proost P, Opdenakker G, van Damme J (1998). Synergistic induction of MCP-1 and -2 by IL- 1 beta and interferons in fibroblasts and epithelial cells. $J$ Leukocyte Biol 63: 364-372.

Sun D, Hu X, Liu X, Whitaker JN, Walker WS (1997). Expression of chemokine genes in rat glial cells: the effect of myelin basic protein-reactive encephalitogenic T cells. J Neurosci Res 48: 192-200. 
Thomas PK, Berthold C-H, Ochoa J (1993). Microscopic anatomy of the peripheral nervous system. Nerve trunks and spinal roots. In: Dyck PJ, Thomas PK, Griffin JW, Low PA, Poduslo JF (eds). Peripheral neuropathy, Vol. 1, WB Saunders, Philadelphia, pp. $28-73$.

Vaddi K, Keller M, Newton RC. (1997). The chemokine factsbook, Academic Press, San Diego.

Venezie RD, Toews AD, Morell P (1995). Macrophage recruitment in different models of nerve injury: lysozome as a marker for active phagocytosis. $J$ Neurosci Res 40: 99-107.
Zettl UK, Gold R, Toyka KV, Hartung HP (1996). In situ demonstration of $\mathrm{T}$ cell activation and elimination in peripheral nervous system during experimental autoimmune neuritis in the Lewis rat. Acta Neuropathol 91: $360-367$.

Zhu J, Mix E, Link H (1998). Cytokine production and the pathogenesis of experimental autoimmune neuritis and Guillain-Barré syndrome. J Neuroimmunol 84: $40-52$. 